\title{
Effect of heat-treatment on luminescence and structure of Ag nanoclusters doped oxyfluoride glasses and implication for fiber drawing
}

\author{
A.S. Kuznetsov ${ }^{a}$, Ngo T. Cuong ${ }^{b}$, V.K. Tikhomirov ${ }^{a}, *$, M. Jivanescu ${ }^{a}$, A. Stesmans ${ }^{\text {a }}$, L.F. Chibotaru ${ }^{\text {b }}$, \\ J.J. Velázquez ${ }^{\text {c }}$, V.D. Rodríguez ${ }^{\mathrm{c}}$, D. Kirilenko ${ }^{\mathrm{d}}$, G. Van Tendeloo $^{\mathrm{d}}$, V.V. Moshchalkov ${ }^{\mathrm{d}}$ \\ a INPAC - Institute for Nanoscale Physics and Chemistry, Katholieke Universiteit Leuven, Belgium \\ ${ }^{\mathrm{b}}$ Division of Quantum and Physical Chemistry, Katholieke Universiteit Leuven, Belgium \\ ${ }^{\mathrm{c}}$ Departamento de Fisica Fundamental y Experimental, Electrónica y Systemas, Universidad de La Laguna, Tenerife, Spain \\ ${ }^{\mathrm{d}}$ EMAT, Electron Microscopy for Materials Science, Universiteit Antwerpen, Belgium
}

\section{A R T I C L E I N F O}

\section{Article history:}

Received 13 March 2011

Received in revised form 5 August 2011

Accepted 5 September 2011

Available online 17 October 2011

\section{Keywords:}

Silver nanoclusters

Oxyfluoride glass

Luminescence

Silver nanoclusters doped fiber

Silver nanocluster formation mechanism

\begin{abstract}
A B S T R A C T
The effect of heat treatment on the structure and luminescence of Ag nanoclusters doped oxyfluoride glasses was studied and the implication for drawing the corresponding fibers doped with luminescent $\mathrm{Ag}$ nanoclusters has been proposed. The heat treatment results, first, in condensation of the Ag nanoclusters into larger Ag nanoparticles and loss of Ag luminescence, and further heat treatment results in precipitation of a luminescent-loss nano- and microcrystalline Ag phases onto the surface of the glass. Thus, the oxyfluoride fiber doped with luminescent $\mathrm{Ag}$ nanoclusters was pulled from the viscous glass melt and its attenuation loss was $0.19 \mathrm{~dB} / \mathrm{cm}$ in the red part of the spectrum; i.e. near to the maximum of $\mathrm{Ag}$ nanoclusters luminescence band. The nucleation centers for the Ag nanoclusters in oxyfluoride glasses have been suggested to be the fluorine vacancies and their nanoclusters.
\end{abstract}

(c) 2011 Elsevier B.V. All rights reserved.

\section{Introduction}

Luminescent Ag nanoclusters have recently attracted a major interest in nanolabels, nanosensors, nano-scale light sources [1-4 and references therein], down-conversion of solar spectrum [5], and other applications. These nanoclusters have extreme small size, from few atoms down to two atoms. This results in some novel properties that are intermediate between bulk materials and the respective single atoms. In particular, $\mathrm{Ag}$ nanoclusters do emit a strong and broad luminescence band, while this luminescence band is absent in bulk silver, due to its metallic character, and it is weak and narrow for single Ag atoms.

Regarding the glass hosts, the Ag nanoclusters have been reported to be dispersed on the surface of $\mathrm{Na}$ containing oxide glasses by means of ion exchange $\mathrm{Ag} \rightarrow \mathrm{Na}$ technique, ion implantation or by direct laser writing with a compulsory heat treatment step [6-10 and references therein]. These techniques have some drawbacks, such as a diffusion limited Ag-ion penetration depth into the glass matrix, which restricts the doped region only to the thin surface layer or to laser written area, as well as the requirement for the extra annealing step. These drawbacks prevent preparation of the bulk glass doped with $\mathrm{Ag}$ nanoclusters with its advantages of arbitrary shaping and fiber drawing.

\footnotetext{
* Corresponding author. Tel.: +32 16 327616; fax: +32 16327983 .

E-mail address: Victor.Tikhomirov@fys.kuleuven.be (V.K. Tikhomirov).
}

Recently, bulk oxyfluoride glasses doped with Ag nanoclusters have been reported $[5,11]$. A conclusion was made that the presence of the fluorine component in the glass is compulsory required to allow preparation of the bulk glasses homogeneously doped with Ag nanoclusters [5]. Still, the mechanism for the formation of Ag nanoclusters in oxyfluoride glasses warrants an investigation.

In this work, the effect of heat treatment on the structure and luminescence of $\mathrm{Ag}$ nanoclusters in oxyfluoride glass hosts has been studied. Ag nanocluster doped fibers have been pulled from the viscous melts of these glasses in the air atmosphere. A model for the formation of $\mathrm{Ag}$ nanoclusters within these glasses and respective fibers has been suggested. The luminescence of $\mathrm{Ag}$ nanoclusters in glass hosts and corresponding fibers may be used in color displays driven by UV light, white light generation under UV pump, tunable light sources/lasers across all visible range, and down-conversion of solar spectrum, e.g. in $[5,11,12]$.

\section{Experimental}

The glass melting procedure was similar to the earlier reported procedure for preparation of similar oxyfluoride glasses doped with lanthanide ions [13,14]. A mixture containing $\mathrm{SiO}_{2}$, $\mathrm{Al}_{2} \mathrm{O}_{3}, \mathrm{CdF}_{2}, \mathrm{PbF}_{2}, \mathrm{ZnF}_{2}$ and $\mathrm{AgNO}_{3}$ powders was batched and melted in a Pt-crucible. $\mathrm{AgNO}_{3}$ was added in wt\%, while other components were batched in mol\%. In particular, an oxyfluoride glass have been prepared with a chemical formula $33\left(\mathrm{SiO}_{2}\right) 9.5(\mathrm{~A}-$ 
$\left.10_{1.5}\right) 32.5\left(\mathrm{CdF}_{2}\right) 19.5\left(\mathrm{PbF}_{2}\right) 5.5\left(\mathrm{ZnF}_{2}\right)$, mol\%, this glass will be called further a base glass; it was doped with different amounts of $\mathrm{AgNO}_{3}$. When the proportion of $\mathrm{SiO}_{2}$ to fluorides was varied, this will be noted further in the text where appropriate.

A $457 \mathrm{~nm}$ line of Ar laser has been used for excitation of luminescence of $\mathrm{Ag}$ nanoclusters in this work, since the laser beam at $457 \mathrm{~nm}$ can propagate some centimeters, while exciting the luminescence, within the obtained glass fibers. The luminescence was collected with a standard probe fiber of $500 \mu \mathrm{m}$ diameter, product of Thorlabs, and delivered to the ANDOR CCD camera DV 887, which could measure the full luminescence spectrum in the time period of the order of $1 \mathrm{~s}$.

The electron spin resonance (ESR) technique was applied aiming at the identification of the nature of $\mathrm{Ag}$ nanoclusters by their spin parameters. Continuous wave ESR spectra have been taken from room temperature down to $4.2 \mathrm{~K}$ using a Jeol FA100 X-band $(\approx 8.9 \mathrm{GHz})$ and a locally constructed K-band $(20.5 \mathrm{GHz})$ spectrometers driven in the adiabatic slow passage mode. Measurements were carried out for both low $(<1 \mathrm{nW})$ and high values of incident microwave power $\mathrm{P} \mu$, using $\approx 100 \mathrm{kHz}$ static field modulation. A co-mounted calibrated Si:P marker sample $(g=1.99869 \pm 0.00002$ at $4.2 \mathrm{~K}$ ) was used for determination of $g$-value of paramagnetic centers. Extensive signal averaging (typically 50-100 runs) was routinely applied to improve spectral quality. More details about ESR experimental methods have been given in Ref. [15].

\section{Results}

\subsection{Effect of heat treatment on luminescence of Ag-nanoclusters doped glasses}

The Ag nanoclusters emit a broad luminescence band, Fig. 1; its intensity increases with Ag-doping level, and the spectrum blueshifts with increasing $\mathrm{SiO}_{2}$ content. As can be seen in the Fig. 1, an undoped glass does not show any luminescence when excited at $457 \mathrm{~nm}$. Therefore the luminescence in $\mathrm{Ag}$ doped glasses is due to Ag dopants/nanoclusters, as confirmed by structural and optical spectroscopy studies in [5]. The blue curve in Fig. 1 corresponds to the glass with enhanced oxide content $38\left(\mathrm{SiO}_{2}\right) 9.5$ (A$\left.1 \mathrm{O}_{1.5}\right) 29.5\left(\mathrm{CdF}_{2}\right) 17.5\left(\mathrm{PbF}_{2}\right) 5.5\left(\mathrm{ZnF}_{2}\right), \mathrm{mol} \%$, this glass was used for drawing the fiber in this work; therefore it is called a fiber precursor glass. Other curves in Fig. 1 correspond to the base glass, as defined in Section 2.

Fig. 2 shows the Ag luminescence spectra after the respective heat treatments (a) and a ratio of the Ag luminescence band inten-

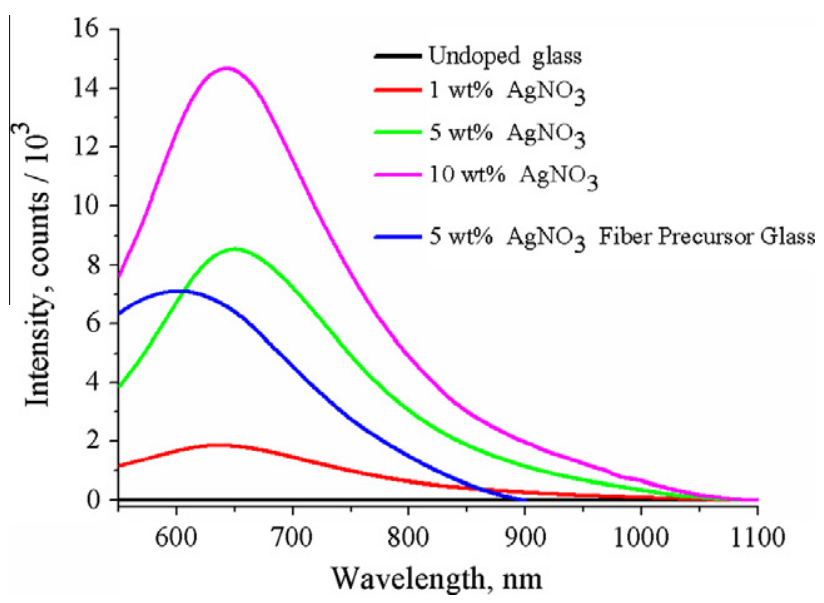

Fig. 1. Luminescence spectra of the undoped and $\mathrm{Ag}$ nanoclusters doped oxyfluoride glasses with indicated doping levels. Excitation was at $457 \mathrm{~nm}$ wavelength and $10 \mathrm{~mW}$ power of Ar laser.
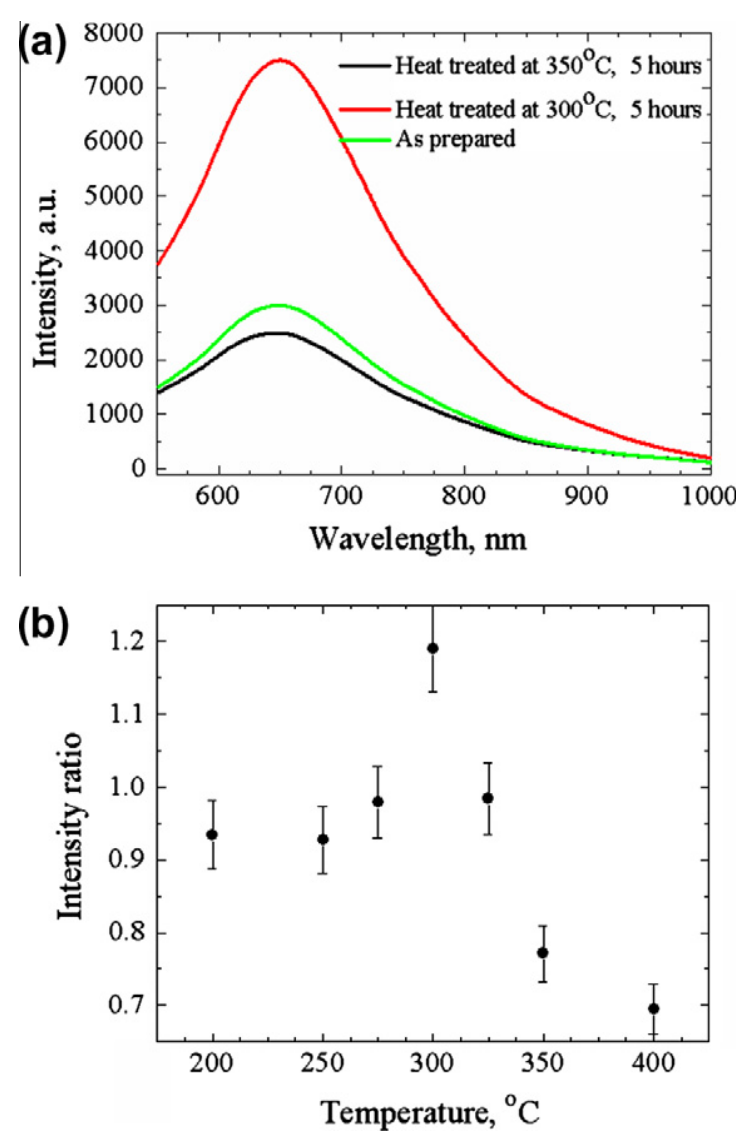

Fig. 2. (a) Luminescence spectra of as prepared and heat treated for $5 \mathrm{~h}$ at indicated temperatures basic glass doped with $10 \mathrm{wt} \%$ of $\mathrm{AgNO}_{3}$; (b) The ratio of the $\mathrm{Ag}$ luminescence band intensities before and after the heat treatments of base glass at the corresponding temperatures; the heat treatment time was set to a short time of 1 hour for all treatment temperatures.

sities before and after the heat treatments. It can be seen that the treatment at about $300^{\circ} \mathrm{C}$ results in some increase of Ag luminescence, when heat treated both at $5 \mathrm{~h}$, Fig. 2a, and $1 \mathrm{~h}$, Fig. $2 \mathrm{~b}$, respectively. The treatment at lower temperatures does not affect $\mathrm{Ag}$ luminescence, Fig. $2 \mathrm{~b}$, whereas the treatment at $350{ }^{\circ} \mathrm{C}$ and higher temperatures indicated in Fig. 2 results in the decrease of Ag luminescence at all studied time treatments. This decrease progresses with increasing the heat treatment temperature, Fig. 2b. A prolonged treatment up to $40 \mathrm{~h}$ and longer, at all temperatures above $300{ }^{\circ} \mathrm{C}$, resulted in gradual suppression of $\mathrm{Ag}$ luminescence. Thus, it can be concluded that $300{ }^{\circ} \mathrm{C}$ is a temperature at which the $\mathrm{Ag}$ ions become mobile in their local surroundings and, consequently, their luminescence is affected by the heat treatment at a corresponding temperature.

\subsection{Effect of heat treatment on the structure of Ag-nanoclusters doped glasses}

X-ray diffraction (XRD) patterns of Ag-doped as-prepared glasses did not show any micro- or nano-crystalline diffraction peaks. An example is presented by black curve in Fig. 3, where only the broad halos corresponding to the amorphous glass host can be seen. Apparently, the Ag nanoclusters in the as-prepared glasses are too small and therefore their diffraction peaks are too broad to be detected in the respective XRD pattern. However, the heat treatment, e.g. at $350^{\circ} \mathrm{C}$ for $30 \mathrm{~h}$ resulted in characteristic diffraction peaks of face centered cubic (fcc) phase of $\mathrm{Ag}$ metal, at $38^{\circ}$ and $44.2^{\circ}$ of $2 \theta$, as indicated by a red curve in Fig. 3 . 


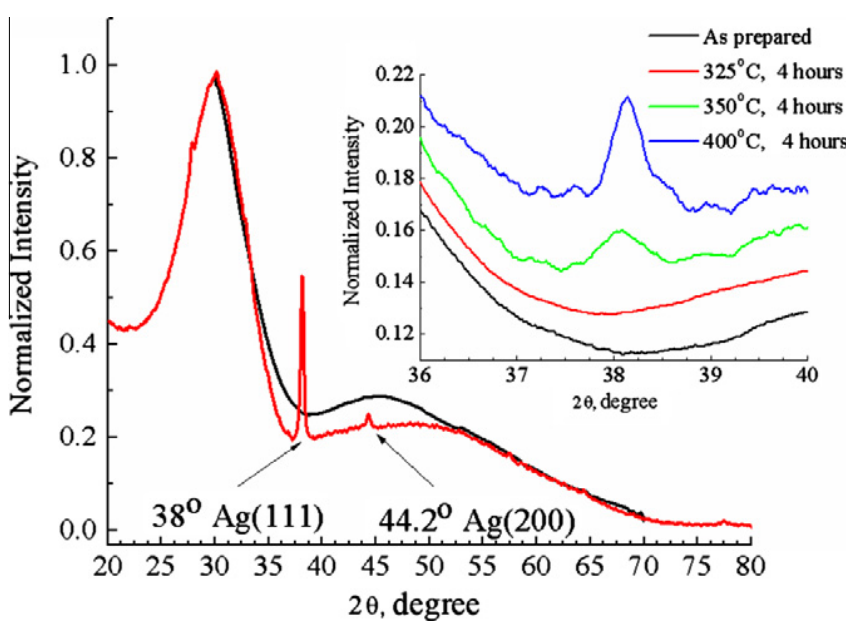

Fig. 3. XRD pattern of the as-prepared base glass doped with $10 \mathrm{wt} \%$ of $\mathrm{AgNO}_{3}$, before (black curve) and after (red curve) heat treatment at $350{ }^{\circ} \mathrm{C}$ for $30 \mathrm{~h}$. The insert indicates the evolution/rise of the $\mathrm{Ag}$ metal diffraction peak at about $38^{\circ}$ of $2 \theta$ with rising the temperature of heat treatment at a fixed treatment time of $4 \mathrm{~h}$, as postsigned. The Miller indices of Ag crystalline planes are indicated in brackets. (For interpretation of the references to colour in this figure legend, the reader is referred to the web version of this article.)

The insert in Fig. 3 depicts an appearance and progressive increase of the main crystalline peak of the (fcc) phase of metal Ag with heat treatment. This increase suggests the growth of Ag metal nanophase/nanoparticles with raising heat treatment temperature. A half height width of the $\mathrm{Ag}$ peak at $38^{\circ}$, after annealing at $350{ }^{\circ} \mathrm{C}$ for $30 \mathrm{~h}$, indicated by red curve in Fig. 3, equals to $0.4^{\circ}$. According to the Scherrer' formula, this indicates an average diameter of about $20 \mathrm{~nm}$ for the grown $\mathrm{Ag}$ metal nanoparticles, in agreement with data of Fig. 4 obtained by transmission electron microscopy (TEM).

Fig. 4a shows low magnification TEM image of the Ag nanoparticles grown on indicated heat treatment of the as-prepared $\mathrm{Ag}$ doped oxyfluoride basic glass. The nanoparticles are mostly spherical with an average diameter about $20 \mathrm{~nm}$. The image in Fig. 4b is especially informative, as it is possible to see here crystallographic planes of Ag metal with the postsigned inter-plane spacing $d_{111}$
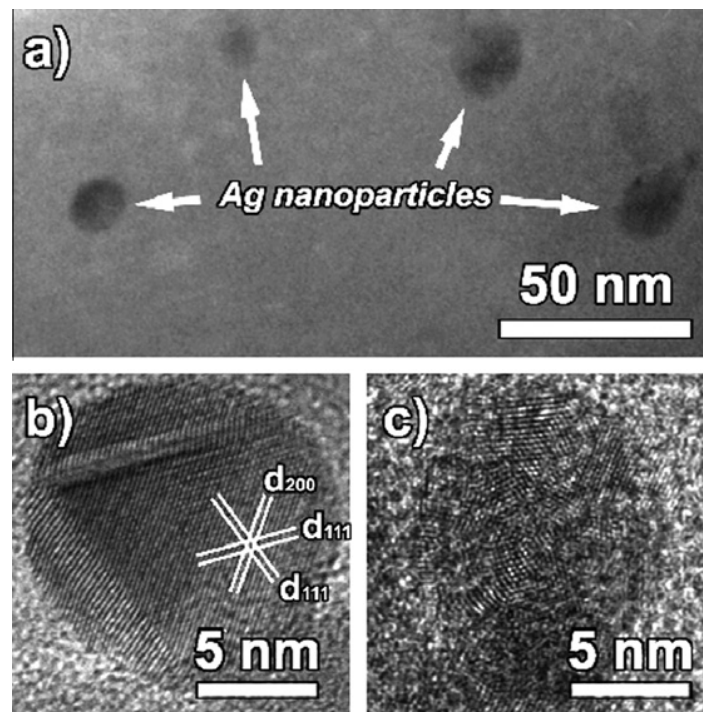

Fig. 4. TEM images of $\mathrm{Ag}$ metal nanoparticles, black color spheres of about $20 \mathrm{~nm}$ diameter, detected in base glass doped with $1 \mathrm{wt} \% \mathrm{AgNO}_{3}$ after heat treatment at $350{ }^{\circ} \mathrm{C}$ for $30 \mathrm{~h}$ (treatment as in Fig. 4). The main crystallographic planes of fcc phase of Ag metal are postsigned in (b) as $d_{111}$ and $d_{200}$, respectively, with the values of these distances corresponding to the Ag metal within an accuracy of $\pm 5 \%$.

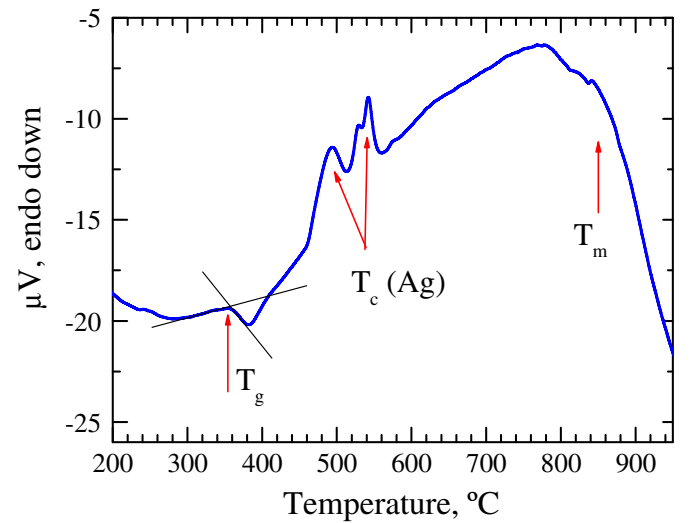

Fig. 5. Differential thermal analysis (DTA) curve of the fiber precursor oxyfluoride glass $38\left(\mathrm{SiO}_{2}\right) 9.5\left(\mathrm{AlO}_{1.5}\right) 29.5\left(\mathrm{CdF}_{2}\right) 17.5\left(\mathrm{PbF}_{2}\right) 5.5\left(\mathrm{ZnF}_{2}\right)$, mol\%, introduced in Fig. 1 , doped with $5 \mathrm{wt} \%$ of $\mathrm{AgNO}_{3}$. The glass transition, $T_{g}$, crystallization, $T_{c}$, and onset melting, $T_{m}$, temperatures are post-signed. The heating rate was $10^{\circ} \mathrm{min}$.

and $d_{200}$. Fig. 4c shows an example of Ag nanoparticle created by coalition of several smaller Ag nanoparticles.

\subsection{Drawing the fiber doped with luminescent Ag nanoclusters}

Fig. 5 shows differential thermal analysis (DTA) curve, which is typical for the oxyfluoride glasses studied in this work. This curve is similar to the DTA curve for analogous Ag-free undoped oxyfluoride glass shown in Fig. 1 in Ref. [13]. In particular, the glass transition temperature is about $T_{g}=370^{\circ} \mathrm{C}$. However, due to the $\mathrm{Ag}$ dopant, the DTA curve in Fig. 5 shows extra crystallization peaks, $T_{c}(\mathrm{Ag})$, between $450^{\circ} \mathrm{C}$ and $550^{\circ} \mathrm{C}$, which respectively correspond to the precipitated crystalline Ag metal phase. We detected this phase by TEM imaging of the glass samples annealed at those high temperatures, as shown for example in Fig. 6. It is seen in Fig. 6, that the Ag metal nanopahse tends to precipitate on the glass surface at this high treatment temperature of $450{ }^{\circ} \mathrm{C}$. Prolonged heat treatment at those high temperatures, corresponding to crystallization of $\mathrm{Ag}$ metal phase, resulted in precipitation of $\mathrm{Ag}$ metal macro-phase on the surface of glass samples, which was easy to see by naked eye and detect by scanning electron microscope,

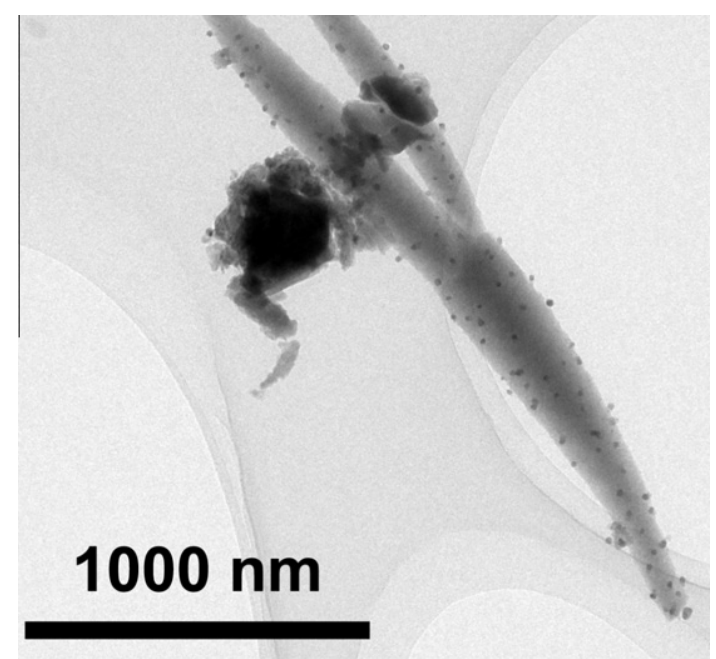

Fig. 6. TEM image of a piece of base precursor glass doped with $5 \mathrm{wt} \% \mathrm{AgNO}_{3}$ after heat treatment at $450{ }^{\circ} \mathrm{C}$ for $10 \mathrm{~min}$; the heat treatment temperature corresponds to the onset of the Ag crystallization peak in Fig. 5. The piece is placed on a standard sample holder consisting of carbon membrane on copper grid. Small black round spots are the $\mathrm{Ag}$ metal nanoparticles precipitated on the surface of the glass piece 

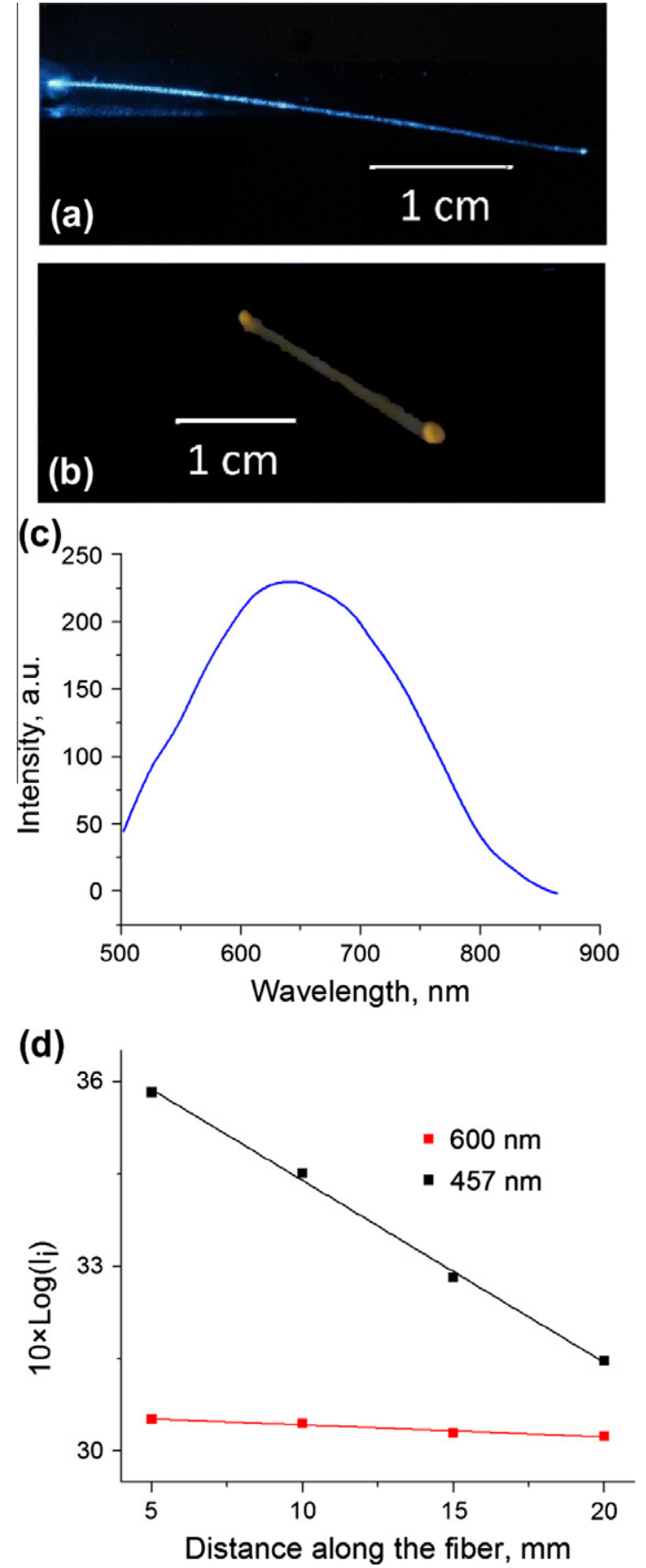

Fig. 7. (a) $457 \mathrm{~nm}$ propagating light launched in the fiber at the left end; (b) luminescent fiber excited from above by invisible light of UV lamp at $366 \mathrm{~nm}$; (c) luminescence spectrum taken from the middle point of the fiber (d) optical loss of the fiber at 457 and $600 \mathrm{~nm}$. The fiber was pulled from the viscous melt and no extra heat treatment steps of the fiber were undertaken.

the glass bulk itself completely devitrified after such heat treatment. The DTA data in Fig. 5 indicate that an Ag-doped fiber may not be drawn from this glass in the temperature range between $T_{g}$ and $T_{c}(\mathrm{Ag})$ because the crystallization peaks are strong and the glass transition peak and crystallization peaks are too close to each other, e.g. in [16 and references therein].

Alternatively, the fiber may be pulled from the viscous melt of this glass at the temperature $T_{m}=850{ }^{\circ} \mathrm{C}$ near to the onset of its melting, Fig. 5; as it was done for a similar $\mathrm{Ag}$-free oxyfluoride glasses in [17]. We have used the tweezers to pull the fiber from the viscous glass melt, when the melt was situated within the hot Pt crucible at $850{ }^{\circ} \mathrm{C}$; the typical pulled fiber length was at about $50-100 \mathrm{~cm}$ and limited by the length of the hand pulling the tweezers.

$T_{m}$ in Fig. 5 is an onset of melting of the glass, while the glass becomes a liquid melt at the temperature above $900{ }^{\circ} \mathrm{C} . T_{m}$ is a temperature around which the viscosity, $\eta$, of the viscous glass melt begins to decrease/increase substantially with increasing/ decreasing the temperature and reaches the value suitable for fiber drawing, $\eta=10^{4.5} \mathrm{~Pa} \mathrm{~s}$, e.g. in [18 and references therein]. $T_{m}$ will depend on the heating/cooling rate of the viscous glass melt; which was $10 \%$ min in Fig. 5 .

Fig. 7 shows the optical loss and luminescence of the fragment of fiber, which was pulled from the viscous glass melt. Excitation of the $\mathrm{Ag}$ nanocluster luminescence of the fibers was carried out either by launching the $457 \mathrm{~nm}$ excitation beam of $\mathrm{Ar}$ laser into the end of the fiber, Fig. 7a, or from above by UV lamp CAMAG at $366 \mathrm{~nm}$, Fig. 7b. It can be seen in Fig. 7a, that the Ag-doped fiber shows a waveguiding effect at $457 \mathrm{~nm}$. A luminescence spectrum of the fiber was taken from its middle point via an orthogonally directed probe fiber bundle connected to the spectrometer, Fig. 7c. The spectrum in Fig. 7c was found to be the same as for the $\mathrm{Ag}$ nanoclusters dispersed in the respective oxyfluoride bulk glass, blue curve in Fig. 1, obtained by casting the same viscous glass melt from which the fiber was pulled. Thus we conclude that the yellowish emission viewed orthogonal to the fiber in Fig. $7 \mathrm{~b}$ and spectrum shown in Fig. 7c originates from the Ag nanoclusters dispersed in oxyfluoride fiber. Spatially uniform yellowish emission from the fiber in Fig. 7b confirms homogenous doping of the fiber with Ag-nanoclusters.

For optical loss measurements, a $457 \mathrm{~nm}$ Ar laser beam was launched in the Ag-doped fiber. A probe fiber directed orthogonal to the Ag-doped fiber was used to collect the light scattered by the Ag-doped fiber. Such method for measurement attenuation loss of planar and channel waveguides has been used in some commercial devices, e.g., Metricon Model 2010 M [19].

Optical attenuation coefficient $A(\mathrm{~dB} / \mathrm{cm})$ at different wavelengths was calculated using the following equation:

$A(\lambda)=10 \times \log _{10}\left(\frac{I_{i}(\lambda)}{I_{i+1}(\lambda)}\right) /(\Delta L)$

where $I_{i}(\lambda)$ is the intensity of light at wavelength $\lambda$ scattered by the Ag-doped fiber and collected with a probe fiber at the distance $L_{i}$ from the fiber entrance, $i$ is an index designating collection point along the fiber, and $\Delta L$ is a distance between the collection points $i$ and $i+1$. Intensities at both the excitation wavelength $(457 \mathrm{~nm})$ and luminescence maximum wavelength $(600 \mathrm{~nm})$ were extracted from the respective luminescence spectra measured at different distances $L_{i}$ from the fiber entrance.

Fig. 7d plots the magnitude of $10 \times \log \left(I_{i}\right)$ at two different wavelengths versus the distance along the fiber. Optical loss at $457 \mathrm{~nm}$ and $600 \mathrm{~nm}$ can be found by calculating the slope of the corresponding straight lines. A loss of $2.95 \mathrm{~dB} / \mathrm{cm}$ was found at $457 \mathrm{~nm}$, while at $600 \mathrm{~nm}$ the loss was substantially lower at $0.19 \mathrm{~dB} / \mathrm{cm}$. The loss at $457 \mathrm{~nm}$ is obviously due to scattering of the launched laser beam. The signal measured at $600 \mathrm{~nm}$ can correspond only to emission of $\mathrm{Ag}$ nanoclusters, which is apparently waveguided along the fiber. Since the attenuation loss at $457 \mathrm{~nm}$ is substantially larger than at $600 \mathrm{~nm}$, this means that the most of the total $\mathrm{Ag}$ emission is excited at the entrance of the fiber. Then the $\mathrm{Ag}$ emission is waveguided along the fiber. Waveguiding of the Ag luminescence along the fiber is also confirmed by visual observation in Fig. 7b, where the fiber ends glow in the stronger yellow-red color compared to the rest of the fiber indicating a waveguiding of the yellow-red emission along the fiber. These loss magnitudes can be considered as good values bearing in mind that the fibers were pulled in the air and without 
protective cladding, while the oxyfluoride fibers are better pulled in the inert gas atmosphere to avoid fiber surface oxidation and resulting extra fiber losses [17].

Since waveguiding in this fiber at $457 \mathrm{~nm}$ takes place, therefore there is no doubts that the waguiding at the longer wavelength of $600 \mathrm{~nm}$ will also take place and with a lower attenuation loss, according to the basics of light scattering theories. When viewing the photoexcited fiber shown in Fig. 7a via the longpass filter, which cut a blue part of the spectrum, we have observed an intensity homogeneous red track along the fiber indicating waveguiding of the red luminescence light along the fiber, which is excited mostly at the enter edge of the fiber.

\subsection{ESR study: Evidence for diamagnetism of Ag nanoclusters}

ESR measurements may generally provide instructive information about the para/diamagnetism of $\mathrm{Ag}$ nanoclusters. However, despite intense study, no Ag-related ESR signal could be detected in the as-prepared glasses doped with Ag nanoclusters neither at room nor at liquid nitrogen or helium temperatures. This situation remained unaltered after subjecting various samples with different Ag doping levels to additional ex situ irradiation treatments in room ambient, including UV, VUV and x-ray excitation. For the latter case, special efforts were given to minimize the time between finishing the x-ray irradiation and cooling down to cryogenic temperature $(\leqslant 77 \mathrm{~K})$ to start up ESR observation in order to limit (charge) recovery processes. By making use of a cavity foreseen with an optical window, neither could any ESR signal be detected by continuous in situ irradiation at room temperature of the sample by the focused full spectrum light of a halogen lamp (150 W) or a $100 \mathrm{~mW} \mathrm{CW}$ laser emitting at $405 \mathrm{~nm}$.

The negative ESR result would indicate the absence of Ag-related paramagnetic centers in these Ag-nanocluster doped glasses, or more precisely, if present only occurring in low densities beyond the ESR detection limit. In the latter view, we may still attempt to infer useful information on the basis of comparison with ESR results obtained on other Ag-doped materials. For example, we may refer to the ESR signal observed in previous work [20], at cryogenic temperatures, from the paramagnetic $\mathrm{Ag}^{2+}$ ions occupying $\mathrm{Ba}^{2+}$ sites in $\beta-\mathrm{BaB}_{2} \mathrm{O}_{4}$ crystals subjected to $60 \mathrm{keV}$ x-ray irradiation. If taking the $\mathrm{Ag}^{2+}$ signal spectral properties (line width, line shape) from that study as representative for the current work, then stepping from the detected Si:P marker ESR signal as reference and the known glass sample size, an upper limit of about $5 \times 10^{14} \mathrm{~g}^{-1}$ is estimated for potentially occurring paramagnetic Ag-related centers in the current glass samples; a very low density indeed. The ESR outcome would thus decline the presence of any substantial amount of paramagnetic $\mathrm{Ag}$ nanoclusters in the studied glasses.

\section{Discussion}

As follows from the above, the Ag ions become mobile in the studied oxyfluoride glass host at treatment at the temperature as low as $300^{\circ} \mathrm{C}$. In oxide glasses however, the heat treatment affects $\mathrm{Ag}$ nanoclusters at substantially higher treatment temperatures of about $500{ }^{\circ} \mathrm{C}$, e.g. in [6-10]. Therefore, the $\mathrm{Ag}^{+}$ions appear to diffuse mostly within the fluoride component of this oxyfluoride glass, which is mostly the $\mathrm{Pb}-\mathrm{Cd}-\mathrm{F}$ network, as confirmed by Raman spectroscopy data [21].

The $\mathrm{PbF}_{2}, \mathrm{CdF}_{2}$ fluorites and $\mathrm{Ag}$ halides are known as the best superionic conductors [22] providing the optimum medium for the creation of $\mathrm{Ag}$ nanoclusters in the $\mathrm{Cd}-\mathrm{Pb}-\mathrm{F}$ matrix at elevated temperatures of already $300{ }^{\circ} \mathrm{C}$. Numerous $\mathrm{F}^{-}$vacancies/F centers are known to exist in the fluorites; their concentration may exceed $1 \%$, page 1241 in [22]. This concentration is comparable to the concentration of Ag dopants used in this work, which therefore can be fully accommodated in the vicinity of the $\mathrm{F}^{-}$vacancies/F centers, which are the structural voids in this oxyfluoride glass, according to the charge compensation mechanism, when $\mathrm{Ag}^{+}$cations substitute for $\mathrm{M}^{2+}$ cation, as described by the following equation:

$\mathrm{M}^{2+}=2 \mathrm{Ag}^{+}=\mathrm{Ag}_{2}^{2+} ; \quad \mathrm{Ag}_{2}^{2+}+\mathrm{e}^{-}=\mathrm{Ag}_{2}^{+}$

where $\mathrm{M}^{2+}$ stands either for $\mathrm{Pb}^{2+}$ or $\mathrm{Cd}^{2+}$. Since the charge of the $\mathrm{Ag}^{+}$ is twice smaller than of $\mathrm{M}^{2+}$, then a pair of $\mathrm{Ag}^{+}$ions is to substitute simultaneously instead of one $\mathrm{M}^{2+}$ cation, according to the left part of Eq. (2). In such case, one $\mathrm{Ag}^{+}$substitutes onto site of $\mathrm{M}^{2+}$ and another $\mathrm{Ag}^{+}$then substitutes onto the neighbor cation hole site, which is typical of fluorite structure; [22,23]. Noteworthy, Cd atom is the next to $\mathrm{Ag}$ in the periodic table thus providing especially easy substitution by Ag. Such substitution is favored by a nearby $\mathrm{F}^{-}$vacancy, which is a structural void and which then will combine with $\mathrm{Ag}_{2}^{2+}$ dimers, according to the right part of Eq. (2), thus nucleating the growth of $\mathrm{Ag}_{2}^{2+}$ dimers.

The result of the substitution described by the charge compensation mechanism of Eq. (2) is depicted schematically for the case of fluorite-type lattice in Fig. 8. Since the short range order of the crystalline counterpart is conserved in the glassy state, especially in these oxyfluoride glasses, as follows from the luminescence [13] and Raman spectroscopy [21] studies, the mechanism depicted in Fig. 8 is assumed to be qualitatively valid also for these oxyfluoride glasses. In Fig. 8, we show two nearby pairs of $\mathrm{Ag}_{2}^{2+}$ dimers depicted by two pairs of blue balls. In each of these pairs, $\mathrm{Ag}$ atoms are linked by a chemical bond indicated by the straight blue line; this bond has an unpaired electron spin indicated by the red arrow.

We have to place two pairs of paramagnetic $\mathrm{Ag}_{2}^{2+}$ dimers nearby to each other due to the experimental observation reported in Section 3.4 about absence of paramagnetic Ag nanoclusters in these glass samples. Being close to each other, the paramagnetic $\mathrm{Ag}_{2}^{2+} \mathrm{di}-$ mers can combine resulting in pairing of electron spins from their

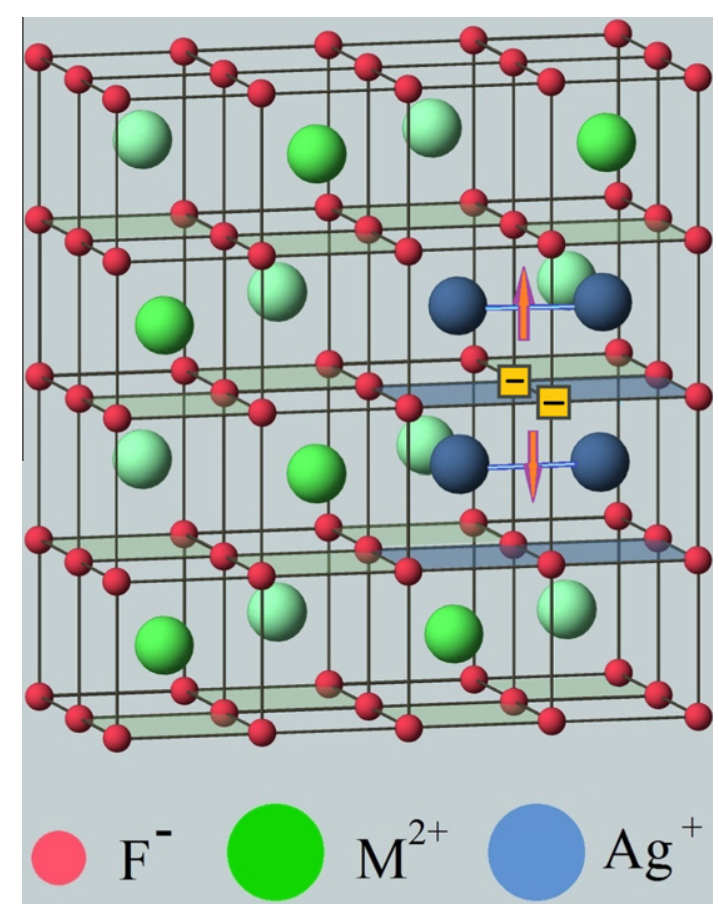

Fig. 8. The charge compensation mechanism for formation of the spin coupled pair of $\mathrm{Ag}_{2}^{2+}$ dimers, or $\mathrm{Ag}_{4}^{2+}$ tetramer, by substitution of two $\mathrm{M}^{2+}$ cations by four $\mathrm{Ag}^{+}$ cations in the fluorite-type lattice. The yellow squares represent $\mathrm{F}^{-}$vacancies (trapped electrons ${ }^{-}$). The blue straight lines represent the chemical bonds between $\mathrm{Ag}$ atoms and the red arrow indicate the spin state on these bonds. 
bonds with creation of diamagnetic $\mathrm{Ag}_{4}^{2+}$ tetramers according to the following equation:

$\mathrm{Ag}_{2}^{+}+\mathrm{Ag}_{2}^{+}=\mathrm{Ag}_{4}^{2+}$

These tetramers are diamagnetic; the energy of the single tetramer is lower that the total energy of two non-interacting $\mathrm{Ag}_{2}^{2+} \mathrm{di}-$ mers. Noteworthy, the nearby nanoclusters of two $\mathrm{F}^{-}$vacancies, indicated by two squares in Fig. 8, serve as nucleation center for the $\mathrm{Ag}_{4}^{2+}$ tetramers. Thus we conclude that the $\mathrm{Ag}_{4}^{2+}$ tetramers depicted in Fig. 8 may be plausible Ag nanoclusters dispersed in these oxyfluoride glasses.

The detail analysis of possible Ag nanoclusters in the fluoritetype lattice, namely their configuration, surroundings, energy levels and spins are addressed in our separate extensive work and it is out of the scope of this paper. Briefly, our results obtained by computing methods, such as Density Functional Theory (DFT) and Complete Active Space Perturbation Theory of Second Order (CASPT2) confirm that the $\mathrm{Ag}_{4}^{2+}$ tetramers are plausible $\mathrm{Ag}$ nanoclusters in these oxyfluoride glasses, while other kinds of nanoclusters such as $\mathrm{Ag}_{2}^{0}, \mathrm{Ag}_{2}^{2+}$ dimers, trimers, other kinds of tetramers do not agree with the experimental luminescence spectra and absence of ESR signal. Finally, only the Ag nanoclusters consisting of four or less $\mathrm{Ag}$ atoms have been argued to be responsible for silver-related luminescence while larger $\mathrm{Ag}$ nanoclusters have been shown to produce negligible luminescence, e.g. in [24-26 and references therein].

\section{Conclusions}

The effect of heat treatment on the structure and luminescence of $\mathrm{Ag}$ nanoclusters dispersed in bulk oxyfluoride glasses has been studied. Unstructured fibers doped with luminescent $\mathrm{Ag}$ nanoclusters have been pulled. The luminescence of $\mathrm{Ag}$ nanoclusters and the attenuation losses in these fibers have been studied. A mechanism for the formation of $\mathrm{Ag}$ nanoclusters in the oxyfluoride glasses involving $F^{-}$vacancies and nanoclusters has been suggested. The luminescence band of this Ag-doped oxyfluoride glass has a potential for application in broad band visible light sources including white light generation and tunable CW lasers, in UV driven panel displays and down-conversion of solar spectrum.

\section{Acknowledgments}

We are grateful to the Methusalem Funding of Flemish Government and Ministerio de Ciencia e Innovacion (MAT2009-12079) for the support of this work. We are grateful to Ministerio de Ciencia e Innovación for financial support (MAT2009-12079) and Gobierno Autónomo de Canarias: Agencia Canaria de Investigación, Innovación y Sociedad de la Información (Sol-SubC200801000286).

\section{References}

[1] L. Konig, I. Rabin, W. Schulze, G. Ertl, Science 274 (1996) 1353.

[2] H.X. Xu, K.S. Suslick, ACS Nano 4 (2010) 3209.

[3] Z. Shen, H. Duan, H. Frey, Adv. Mater. 19 (2007) 349.

[4] I. Díez, M. Pusa, S. Kulmala, H. Jiang, A. Walther, A.S. Goldman, A. Müller, O. Ikkala, R. Ras, Angew. Chem. Int. Ed. 48 (2009) 2122.

[5] V.K. Tikhomirov, V.D. Rodríquez, A. Kuznetsov, D. Kirilenko, G. Van Tendeloo, V.V. Moshchalkov, Opt. Express 18 (2010) 22032

[6] M. Ferrari, F. Gonella, M. Montagna, C. Tosello, J. Appl. Phys. 79 (1996) 2055

[7] G. Nunzi Conti, V.K. Tikhomirov, M. Bettinelli, S. Berneschi, M. Brenci, B. Chen, S. Pelli, A. Speghini, G.C. Righini, Opt. Eng. 42 (2003) 2805.

[8] H.-E. Mahnke, I. Zizak, P. Schubert-Bischoff, V. Koteski, Mater. Sci. Eng. B 149 (2008) 200

[9] M. Eichelbaum, K. Rademann, A. Hoell, D.M. Tatchev, W. Weigel, R. Stoßer, G. Pacchioni, Nanotechnol 19 (2008) 135701.

[10] Y. Dai, X. Hu, C. Wang, D. Chen, X. Jiang, C. Zhu, B. Yu, J. Qiu, Chem. Phys. Lett. 439 (2007) 81

[11] H. Guo, X. Wang, J. Chen, F. Li, Opt. Express 18 (2010) 18900.

[12] V.D. Rodriguez, V.K. Tikhomirov, J. Mendez-Ramos, A.C. Yanes, V.V. Moshchalkov, Sol. Energy Mater. Sol. Cells 94 (2010) 1612.

[13] V.K. Tikhomirov, D. Furniss, I.M. Reaney, M. Beggiora, M. Ferrari, M. Montagna, R. Rolli, Appl. Phys. Lett. 81 (2002) 1937.

[14] V.K. Tikhomirov, L.F. Chibotaru, D. Saurel, P. Gredin, M. Mortier, V.V. Moshchalkov, Nano Lett. 9 (2009) 721.

[15] A. Stesmans, Phys. Rev. B 48 (1993) 2418.

[16] V.K. Tikhomirov, D. Furniss, J.A. Savage, P.D. Mason, D.A. Orchard, K.L. Lewis, Infrared Phys. Technol. 45 (2004) 115.

[17] P.A. Tick, N.F. Borelli, L.K. Cornelius, M.A. Newhouse, J. Appl. Phys. 78 (1995) 6367.

[18] A.B. Seddon, V.K. Tikhomirov, H. Rowe, D. Furniss, J. Mater. Sci: Mater. Electron. 18 (2007) S145.

[19] <http://www.metricon.com/specs3.html>.

[20] W. Hong, D. Perlov, L.E. Halliburton, J. Phys. D.: Appl. Phys. 36 (2003) 2605

[21] V.K. Tikhomirov, M. Ferrari, M. Montagna, L.F. Santos, R.M. Almeida, Europhys. Lett. 64 (2003) 529.

[22] S. Hull, Rep. Prog. Phys. 67 (2004) 1233.

[23] P. Boutinnand, A. Monnier, H. Bill, J. Phys.: Condens. Matter 6 (1994) 8931.

[24] I. Rabin, W. Schulze, G.J. Ertl, J. Chem. Phys. 108 (1998) 5137.

[25] L. Maretti, P.S. Billone, Y. Liu, J.C. Scaiano, J. Am. Chem. Soc. 131 (2009) 13972.

[26] I. Díez, R.H.A. Ras, Nanoscale 3 (2011) 1963. 